\title{
An Exploration of Quality of Life Contributors for Stroke Survivors: Potential Implications for Service Delivery Within the Community Rehabilitation Context
}

\author{
Gaylea Fritsch \\ Queensland Health, Metro South Health Service, Community Adult Rehabilitation Service, \\ gayleafritsch@gmail.com \\ Sarah Patterson \\ Queensland Health, Metro South Health Service, Community Adult Rehabilitation Service, \\ sarah.patterson@health.qld.gov.au \\ Anita Blight \\ Queensland Health, Metro South Health Service, Community Adult Rehabilitation Service, \\ anita.blight@health.qld.gov.au \\ Renaye Daniells \\ Queensland Health, Metro South Health Service, Community Adult Rehabilitation Service, \\ Renaye.Daniells@health.qld.gov.au
}

Follow this and additional works at: https://nsuworks.nova.edu/ijahsp

Part of the Rehabilitation and Therapy Commons

\section{Recommended Citation}

Fritsch G, Patterson S, Blight A, Daniells R. An Exploration of Quality of Life Contributors for Stroke Survivors: Potential Implications for Service Delivery Within the Community Rehabilitation Context. The Internet Journal of Allied Health Sciences and Practice. 2020 Jan 01;18(4), Article 6.

This Manuscript is brought to you for free and open access by the College of Health Care Sciences at NSUWorks. It has been accepted for inclusion in Internet Journal of Allied Health Sciences and Practice by an authorized editor of NSUWorks. For more information, please contact nsuworks@nova.edu. 


\title{
An Exploration of Quality of Life Contributors for Stroke Survivors: Potential Implications for Service Delivery Within the Community Rehabilitation Context
}

\begin{abstract}
Purpose: Community rehabilitation services typically assist stroke survivors with function, participation, and quality of life. Many factors have been found to influence the overall quality of life including selfidentity, control, social supports, personality, and participation in valued activities. This review explored the possible contributing quality of life factors for stroke survivors within a community rehabilitation context to assist with further development of service delivery within this clinical area. Method: A purposive sample of clients with stroke $(n=20)$ was selected based on their overall quality of life change during their rehabilitation program as measured on the World Health Organisation Quality of Life Questionnaire. Clients with the largest positive and negative quality of life changes were included. A clinical record review of client medical records was undertaken of these stroke survivors to identify and describe common themes that may be related to quality of life. Results: Five general themes emerged relating to possible contributing factors to quality of life for clients participating in this community stroke rehabilitation setting including transiting between hospital and community, flexibility of service delivery model, strength of family and household relationships, acceptance and expectation of both service delivery and functional levels, and ongoing co-morbid medical issues. Conclusions: This review suggests that community rehabilitation service models of care should be flexible and tailored to client needs and goals to enable a true "clientcentered" approach. Social and behavioural paradigms should be incorporated within the community rehabilitation settings. Services should focus on personal factors such as the stroke survivor's adjustment to their situation, personality factors, and outcome expectations. Consideration also needs to be given to the overall continuum of care of health care services.
\end{abstract}

\section{Author Bio(s)}

Gaylea Fritsch, BSpPath, is a Senior Speech Pathologist in the Community Adult Rehabilitation Service within Metro South Health Service in Brisbane, Queensland, Australia.

Sarah Patterson, BOccThy(Hons), is an Advanced Occupational Therapist in the Community Adult Rehabilitation Service within Metro South Health Service in Brisbane, Queensland, Australia.

Anita Blight, BOccThy(Hons), is an acting Advanced Occupational Therapist in the Community Adult Rehabilitation Service within Metro South Health Service in Brisbane, Queensland, Australia.

Renaye Daniells, BOccThy, is an acting Team Leader in the Community Adult Rehabilitation Service within Metro South Health Service in Brisbane, Queensland, Australia.

\section{Acknowledgements}

The authors would like to acknowledge the staff from Metro South Health Service for their support of this review, including the Community Adult Rehabilitation Service Team and Program Co-ordinator. 


\title{
TIJAHSP \\ The Internet Journal of Allied Health Sciences and Practice \\ Dedicated to allied health professional practice and education \\ Vol. 18 No. 4 ISSN 1540-580X
}

\section{An Exploration of Quality of Life Contributors for Stroke Survivors: Potential Implications for Service Delivery within the Community Rehabilitation Context}

\author{
Gaylea Fritsch \\ Sarah Patterson \\ Anita Blight \\ Renaye Daniells \\ Queensland Health
}

Australia

\begin{abstract}
Purpose: Community rehabilitation services typically assist stroke survivors with function, participation, and quality of life. Many factors have been found to influence the overall quality of life including self-identity, control, social supports, personality, and participation in valued activities. This review explored the possible contributing quality of life factors for stroke survivors within a community rehabilitation context to assist with further development of service delivery within this clinical area. Method: A purposive sample of clients with stroke $(n=20)$ was selected based on their overall quality of life change during their rehabilitation program as measured on the World Health Organisation Quality of Life Questionnaire. Clients with the largest positive and negative quality of life changes were included. A clinical record review of client medical records was undertaken of these stroke survivors to identify and describe common themes that may be related to quality of life. Results: Five general themes emerged relating to possible contributing factors to quality of life for clients participating in this community stroke rehabilitation setting including transiting between hospital and community, flexibility of service delivery model, strength of family and household relationships, acceptance and expectation of both service delivery and functional levels, and ongoing co-morbid medical issues. Conclusions: This review suggests that community rehabilitation service models of care should be flexible and tailored to client needs and goals to enable a true "client-centered" approach. Social and behavioural paradigms should be incorporated within the community rehabilitation settings. Services should focus on personal factors such as the stroke survivor's adjustment to their situation, personality factors, and outcome expectations. Consideration also needs to be given to the overall continuum of care of health care services.
\end{abstract}

Keywords: stroke, quality of life, community rehabilitation, model of care 


\section{INTRODUCTION}

Community rehabilitation services are integral to stroke care, typically offering a holistic client-centered approach to health care following hospital discharge. ${ }^{1}$ Although there does not appear to be a standard model of care for community rehabilitation services, it is generally accepted that such services are ideally underpinned by the International Classification of Functioning, Disability, and Health (ICF).2,3 As such, community rehabilitation services typically utilize psychosocial and physical interventions, activity-based therapy, and community participation to assist stroke survivors to return to their previous life roles. Fundamentally, these services focus on improving quality of life $(\mathrm{QoL})$ in the context of a stroke survivor's capabilities and social situation. ${ }^{4}$

Literature indicates many factors can influence a stroke survivor's quality of life (QoL). Moeller and Carpenter (2013) found stroke survivors' QoL was determined by the perceived impact on an individual's sense of self-identity. ${ }^{5}$ Specifically, improved QoL was associated with a sense of control, engagement in valued activities, and relationships with family and friends. ${ }^{5}$ Coping and personal adaptation skills were also found to have a positive impact on healthrelated QoL and were associated with stroke survivors pursuing goals. ${ }^{6}$ Conversely, some personality traits such as neuroticism, pain, and depression were associated with lower QoL.6-8 The severity of impairment including physical, communication, and cognitive deficits were also associated with less positive QoL outcomes. ${ }^{9,10}$

Service delivery factors such as psychological interventions, client education, and participation in valued activities have been shown to be positive contributors to QoL.11,12 Whilst impairment-based therapy has a positive impact on motor function, Sehatzadeh (2015) found a limited change in stroke survivors' overall QoL following impairment-based intensive therapy. ${ }^{13}$ It has been hypothesized that while physical factors impact stroke survivors during the acute phase, psychological factors including life adjustment post-hospital discharge affect health-related QoL during the chronic phase of stroke recovery. ${ }^{6}$

\section{Community Rehabilitation Service Delivery Context}

The Metro South Community Adult Rehabilitation Service (CARS) in Brisbane, Queensland, offers multi-disciplinary allied health services to assist clients with community-related goals following hospital discharge. Therapists within the team include physiotherapists, occupational therapists, speech pathologists, social workers, and dietitians. Approximately $35 \%$ of clients seen in the service have a diagnosis of stroke. Whilst the service model of CARS aligns with the ICF, therapists within the team have had additional training within social and behavioral paradigms to assist with their client care and underpin service delivery. These include self-management principles, health behavior change techniques, and the concepts of the social determinants of health. ${ }^{14}$

Utilizing the blend of traditional rehabilitation principles with social and behavioral paradigms as described, CARS utilizes a comprehensive client focussed initial screening tool to establish a client's functional status post-stroke (compared to pre-stroke), goals, contextual and social situation, and barriers to participation. Within the service, clients receive individualized therapy either in their home, local community, or community health center depending on their individual needs and goals. A weekly exercise and education group is also offered. Outcome measures are completed pre- and post-intervention, including the World Health Organisation Quality of Life Questionnaire (WHO-QoL), to capture the client's progress through their community rehabilitation journey. ${ }^{15}$

Significant variations within stroke clients' change scores on the WHO-QoL assessment were noted by therapists working within the team. This suggested a varied service influence on QoL of stroke survivors through the community rehabilitation journey. Therapists were keen to gain further understanding of the factors that may influence QoL to assist with more effective and appropriately targeted intervention

This clinical record exploration aimed to gain an understanding of factors associated with stroke survivor's QoL within the context of the CARS program to assist with the delivery of appropriate models of care.

\section{METHOD}

\section{Evaluation Method and Timeline}

This clinical record review was completed in accordance with the processes recommended by Sarkar and Sesadri (2014). ${ }^{16}$ This included defining the clinical parameters of the medical record to be reviewed, the development of a data extraction priority code, and the evaluation of the dataset with multiple researchers to reduce bias and confirm data patterns. 
The defined data set included all client medical records pertaining to their community rehabilitation program, including the initial screening tool, professional specific assessments, referrals, correspondences, and progress notes for stroke survivors who attended CARS during the period 2012-2016. Twenty (20) client medical records were selected for review and evaluation from the complete data set of stroke survivors who attended CARS during the period. Ten records with the highest positive change in QoL and ten records with the largest negative change in QoL were utilized for data extraction.

The data set was reviewed for accuracy by the research team, and because of formalized initial screening tool and documentation requirements within the service, no incomplete data sets were found. Client confidentiality was maintained as all researchers were clinicians working in the team with access to the clients' records. Once the data was extracted, it was stored in a de-identified spreadsheet on a secure computer location.

A data extraction priority code was created by all four researchers from the CARS team (comprising of three occupational therapists and a speech pathologist) during the first two clinical record reviews. The two records that were initially chosen for review were the client with the largest positive change in Qol and the client with the largest negative change in QoL. These were identified by unanimous agreement to guide future analyses and categorized into five overall headings:

1. Demographics: Gender, Age, Category of Stroke, Suburb, Primary Language, Country of Origin, Living Situation, Past Medical History.

2. Levels of Function: Previous level of function, Level of function post-stroke.

3. Stroke Journey: GP, Stroke pathway, LOS with CARS service, Time post-stroke when commencing treatment with CARS.

4. Personal and Social Factors: Personal Attributes, Social Factors.

5. CARS intervention: number of case conferences, was a care coordinator was assigned to the patient? Was the initial assessment procedure completed? Was goal setting completed? The style of therapy (1:1 or groups), number of professionals involved, therapy specifics, total number of sessions.

These four researchers utilized the established data extraction priority codes to collect data from the two initial clinical record reviews and thoroughly establish coding rules and consistency for inter- and intra-rater reliability. Each of the priority codes was located within the client medical chart and appropriate data was recorded under the agreed priority areas. Levels of function, personal attributes, and social factors details were taken directly from the medical record as they were commonly recorded information by the treating therapists. Level of function was typically recorded as a measure of their mobility ability as well as their ability to participate in self-care, domestic, and community-based activities. Personal attributes were frequently documented within the 'subjective' comments by therapists in each medical note and frequently included levels of motivation, and relevant personality traits. Social factors were generally documented as friends and family able to assist the client as well as the descriptors as to the quality of these relationships. This process took approximately one hour per data set.

Researchers were then paired to form two research teams. The researchers were paired from different treatment subteams within CARS to reduce the likelihood of clients being known to both the researchers, minimizing bias. These two research groups completed comprehensive chart reviews for the remaining eighteen clients across the two cohorts. The above categories were utilized to uncover possible ideas and concepts related to both client and service factors. In addition, researchers recorded any other personal features of clients or their experience with the service as deemed relevant that was not covered by the data extraction priority codes. Both team members had to agree upon the relevance of the additional data extraction. Details of findings were de-identified and stored in an electronic database spreadsheet.

Following the clinical record reviews and before completing the data analysis, the four researchers met to further discuss each data subset and the extraction processes to assist with internal consistency.

\section{Participants}

A purposive sample of clients was selected, based on their total changes in QoL as measured by the WHO-QoL assessment pre and post-intervention. Two client chart reviews were completed initially by the four researchers together, including one with the largest positive change in QoL (Cohort 1) and one with the largest negative change in

(c) The Internet Journal of Allied Health Sciences and Practice, 2020 
QoL (Cohort 2). Following this, each pair of researchers completed the clinical audit reviews alternating between positive and negative QoL until it was felt that data saturation was reached. A final clinical audit was completed to ensure consistency in the number of reviews within each cohort.

In total, 20 client clinical record reviews were completed

1. Cohort 1: 10 client charts with the largest positive change in QoL, as measured by the pre- and post-WHOQoL assessments.

2. Cohort 2: 10 client charts with the largest negative change in QoL, as measured by the pre- and post-WHOQoL assessments.

Table 1. Characteristics of stroke survivors selected

\begin{tabular}{|c|c|c|}
\hline Characteristic & $\begin{array}{c}\text { Clients with Greatest Positive } \\
\text { QoL Changes }(\mathrm{N}=10)\end{array}$ & $\begin{array}{c}\text { Clients with Greatest Negative } \\
\text { QoL Changes }(\mathrm{N}=10)\end{array}$ \\
\hline Mean Age in Years & $62.2(\mathrm{SD}=12.34)$ & $69.9(\mathrm{SD}=13.33)$ \\
\hline Gender (M:F) & $4(40 \%): 6(60 \%)$ & $6(60 \%): 40(40 \%)$ \\
\hline $\begin{array}{l}\text { Category of Stroke } \\
\text { Haemorrhagic } \\
\text {-Right } \\
\text {-Left }\end{array}$ & $\begin{array}{l}1(10 \%) \\
1(10 \%)\end{array}$ & $\begin{array}{l}1(10 \%) \\
1(10 \%)\end{array}$ \\
\hline $\begin{array}{l}\text { Partial Anterior Circulation } \\
\text { Infarction (PACl) } \\
\text {-Right } \\
\text { - Left }\end{array}$ & $\begin{array}{l}2(20 \%) \\
2(20 \%)\end{array}$ & $\begin{array}{l}1(10 \%) \\
4(40 \%)\end{array}$ \\
\hline $\begin{array}{l}\text { Lacunar Infarction (LACI) } \\
\text {-RIGHT } \\
\text {-LEFT }\end{array}$ & $\begin{array}{c}2(20 \%) \\
0(0 \%)\end{array}$ & $\begin{array}{l}1(10 \%) \\
1(10 \%)\end{array}$ \\
\hline $\begin{array}{l}\text { Posterior Circulation } \\
\text {-Right } \\
\text {-Left } \\
\text {-Bilateral }\end{array}$ & $\begin{array}{l}1(10 \%) \\
0(0 \%) \\
1(10 \%)\end{array}$ & $\begin{array}{l}1(10 \%) \\
0(0 \%) \\
0(0 \%)\end{array}$ \\
\hline Birthplace (recorded as Australia) & $4(40 \%)$ & $5(50 \%)$ \\
\hline $\begin{array}{l}\text { Social Situation } \\
\text { Live alone } \\
\text { Lives with family } \\
\text { Lives with others }\end{array}$ & $\begin{array}{l}2(20 \%) \\
7(70 \%) \\
1(10 \%)\end{array}$ & $\begin{array}{c}0(0 \%) \\
10(100 \%) \\
0(0 \%)\end{array}$ \\
\hline $\begin{array}{l}\text { Rehabilitation Pathway } \\
\text { From inpatient rehabilitation } \\
\text { hospital } \\
\text { From outpatient department } \\
\text { associated with rehabilitation } \\
\text { From acute care hospital } \\
\text { ward } \\
\text { From outpatient department }\end{array}$ & $\begin{array}{l}5(50 \%) \\
2(20 \%) \\
3(30 \%) \\
0(0 \%)\end{array}$ & $\begin{array}{l}5(50 \%) \\
1(10 \%) \\
1(10 \%) \\
2(20 \%)\end{array}$ \\
\hline $\begin{array}{l}\text { Delayed Referral (i.e., greater than } 14 \\
\text { days between referral and initial CARS } \\
\text { contact) }\end{array}$ & $0(0 \%)$ & $3(30 \%)$ \\
\hline
\end{tabular}

\section{Ethical Approval}

An exemption from a full Human Research Ethics Review was obtained from the Princess Alexandra Hospital Human Research Ethics Committee (HREC/17/QPAH/309). 


\section{Data Analysis}

A thematic analysis was completed with the extracted data to explore the emergent themes and consider possible relationships between them. ${ }^{17}$ This analysis process was manually completed in two stages. Firstly, the de-identified data within the spreadsheet was read and re-read by each member of the paired research team and discussions were undertaken by each pair as to possible recurrent key concepts and ideas. Following this, the four researchers met to compare and combine the key concepts across the entire data set. The agreed key concepts were placed on a whiteboard, discussed thoroughly, and mapped to develop overall themes based on the consensus of the majority. The agreed overall themes were reviewed against the raw data extracted and original patterns identified to check the consistency. Potential relationships between the agreed themes were then explored and discussed within the research group.

\section{RESULTS}

Five general themes emerged from the data relating to possible contributing factors to QoL for clients participating in community stroke rehabilitation:

1. Transition between services

2. Flexibility of service delivery model

3. Family and household relationships

4. Acceptance and expectation

5. Ongoing medical issues

\section{Transition to CARS}

All stroke clients with positive changes to QoL were followed up by CARS on receipt of the referral and had received other therapy immediately before CARS contact. A typical referral pathway within this group was admission to the hospital with subsequent inpatient rehabilitation stay, referred to CARS on discharge, and contacted by CARS on receipt of the referral, typically within 14 days (represented by participant 10).

Some clients with stroke having negative QoL scores experienced a delayed referral to CARS for various reasons. In two cases (participants $16 \& 18$ ) the referral was not received by CARS, with the clients having to follow up for the referral location. One participant (participant 13) had stroke symptoms for some time with no previous access to therapy until a formal diagnosis of stroke was made eight months later and subsequent CARS referral.

\section{Flexibility of Service}

Clients that recorded a positive change in QoL appeared to receive a mixture of therapy modes within CARS that were responsive to their concerns and individual goals. In these instances, therapy and goals frequently were spread across numerous ICF domains. Session number, location, and professions differed for each of these clients, suggesting that a flexible, client focussed model was provided for this client group. For example, in one instance, therapy was increased post-fall at the client's request to assist with confidence-building and community participation (participant 6 ). Another client received a significant amount of care coordination support via liaison with their general practitioner and other departments, social work, and one-on-one therapy as they declined possible group intervention (participant 7).

In comparison, half (50\%) of the participants in the negative WHOQoL cohort did not receive flexible multi-modal, multidisciplinary therapy. The reasons participants did not receive this type of therapy were varied. Three participants in the negative WHOQoL cohort received input from one allied health discipline at the clinician's discretion. Other participants were offered multidisciplinary intervention; however, they declined, as their focus was on one particular goal (participants $18 \& 19)$. In addition, three participants $(13,17, \& 18)$ received group therapy as the main mode of therapy with limited one-to-one tailored input.

\section{Family and Household Relationships}

There appeared to be a strong association between the quality of family and household relationships and reported QoL. The majority of clients who reported positive changes in QoL indicated strong support from family members and/or people in their communities. Initial assessments with these clients reported these positive family and household relationships such as flatmates who assist with transport and supportive families and neighbors. Positive family and community support also appeared to foster engagement in the rehabilitation process. For example, participant 8 was initially reluctant to engage in therapy; however, with encouragement from his wife, he completed treatment with good QoL outcomes. 
Those with more difficult relationships in their family or household tended to be those with negative QoL change scores. Forty percent $(40 \%)$ of this group reported significant strain in their family relationships that was impacting their ability to participate in rehabilitation (although it is acknowledged that many of these relationships had been strained before the stroke). For example, participant 11 experienced significant strain between herself and her daughter, with whom she was living during her rehabilitation. In addition, clients with negative QoL change scores were generally provided with significant psychological support (primarily via Social Work) to address carer strain and relationship tension.

\section{Acceptance and Expectation}

Clients who reported positive changes in their QoL appeared to have realistic expectations of therapy and set functional ability goals, and as such, were generally satisfied with their therapy outcomes. Some clients reported positive changes in QoL regardless of whether they returned to their previous level of functioning. For example, participant 4 chose not to return to work but was also very accepting of his level of functioning. This participant reported increased confidence in managing on his own and no longer feeling depressed.

About a third of clients who experienced negative QoL changes tended to be dissatisfied with their functional status, have unrealistic expectations regarding their recovery, and high expectations overall. Some of the clients who experienced negative changes in their QoL appeared to have high expectations of themselves and the recovery process (participant 15) and as such, were disappointed with their functional ability post-stroke (participant 19).

\section{Ongoing Medical Issues}

Both groups of clients within the positive and negative QoL change groups experienced ongoing and often chronic medical challenges following their strokes during the community rehabilitation process. It was noted that clients who experienced positive changes in QoL either did not have co-morbidities that were a barrier to rehabilitation or were able to manage their other medical conditions, allowing for rehabilitation and role participation. For example, participant 1 experienced seizures post-stroke, but the participant was able to manage these with medication. Participant 2 reported improvements with mood, fatigue, and overall health following a medical review and subsequent medication change.

About a third of clients who experienced negative changes in QoL appeared to have ongoing medical issues which appeared to impact on their recovery and their ability to engage with the rehabilitation program. Examples included waiting for left shoulder surgery (participant 13), cardiac history and pain (participant 17), and sciatic pain (participant 19).

\section{DISCUSSION}

The purpose of this review was to uncover potential contributors that may influence a stroke survivor's QoL in the context of community rehabilitation to ultimately assist with the improvement of service delivery models and intervention. Overall, this review identified an array of possible contributors to QoL within this context. Whilst some of these contributors are directly related to service delivery (transition between services and flexibility of service delivery), client contextual related contributors (such as social relationships, acceptance, and medical conditions) are also contributory. These contextual factors may still be able to be positively affected within service models of stroke care. The challenge for service delivery lies in the development of models of care which are focussed on supporting all elements associated with quality of life within the community rehabilitation paradigm. Table 2 outlines the key themes from this snapshot review and the potential model of care implications for community-based stroke rehabilitation services.

In conjunction with local service delivery models, consideration needs to be given to the overall continuum of care of health care services. Stroke care typically begins with inpatient care and then continues across an array of healthcare settings within the community. ${ }^{1}$ These transitions are difficult for patients and caregivers, with psychosocial needs often going unmet. ${ }^{18}$ The results of this snapshot review suggest that a smooth service transition may be linked to QoL posthospital discharge. This notion is supported by literature which suggests that transitions home were influenced by education regarding preparation for returning home and the follow-up therapy they would receive. ${ }^{19}$ Coordination of discharge from hospital to community services is also recommended by the Australian Clinical Guidelines for Stroke Management. ${ }^{1}$

(c) The Internet Journal of Allied Health Sciences and Practice, 2020 
Table 2. Potential service delivery impacts associated with QoL contributors

\begin{tabular}{|c|c|c|c|c|}
\hline \multirow[t]{2}{*}{ Contributor to QoL } & \multicolumn{2}{|c|}{ Possible impact on QoL } & \multicolumn{2}{|c|}{ Potential Service Delivery Impact } \\
\hline & $\begin{array}{c}\text { Positive } \\
\text { Association }\end{array}$ & $\begin{array}{c}\text { Negative } \\
\text { Association }\end{array}$ & $\begin{array}{l}\text { Initial Meeting and } \\
\text { Screening }\end{array}$ & $\begin{array}{c}\text { Intervention / } \\
\text { Models of Care }\end{array}$ \\
\hline $\begin{array}{l}\text { Transition Between } \\
\text { Services }\end{array}$ & $\begin{array}{l}\text { Smooth and timely } \\
\text { transitions between } \\
\text { continuum of stroke } \\
\text { services }\end{array}$ & $\begin{array}{l}\text { Delayed or } \\
\text { disjointed transition } \\
\text { across the } \\
\text { continuum }\end{array}$ & $\begin{array}{l}\text { Establish links with } \\
\text { services, common } \\
\text { referrals, and trust } \\
\text { across services. } \\
\text { Initial screening } \\
\text { process that are } \\
\text { aware / sensitive to } \\
\text { client's 'journey' to } \\
\text { community rehab } \\
\text { services. }\end{array}$ & $\begin{array}{l}\text { Smooth seamless } \\
\text { coordinated } \\
\text { approach to stroke } \\
\text { care across the } \\
\text { continuum. }\end{array}$ \\
\hline $\begin{array}{l}\text { Service Delivery } \\
\text { Model }\end{array}$ & $\begin{array}{l}\text { Flexible, multi- } \\
\text { disciplinary, varied, } \\
\text { client goal focussed } \\
\text { model of service } \\
\text { delivery }\end{array}$ & $\begin{array}{l}\text { Single profession, } \\
\text { fixed, or rigid model } \\
\text { of care }\end{array}$ & $\begin{array}{l}\text { Screening tools } \\
\text { designed with focus } \\
\text { on client's overall } \\
\text { goals and needs, } \\
\text { rather than } \\
\text { professional specific } \\
\text { review. }\end{array}$ & $\begin{array}{l}\text { Flexible client } \\
\text { focussed service } \\
\text { delivery models, } \\
\text { underpinned by } \\
\text { trans-professional } \\
\text { staff within multi- } \\
\text { disciplinary teams, } \\
\text { with access to an } \\
\text { array of treatment } \\
\text { modalities dependent } \\
\text { on client need. }\end{array}$ \\
\hline Family Relationships & $\begin{array}{l}\text { Strong support from } \\
\text { family members } \\
\text { and/or people in } \\
\text { their communities }\end{array}$ & $\begin{array}{l}\text { Difficult } \\
\text { relationships in their } \\
\text { family or household }\end{array}$ & $\begin{array}{l}\text { Initial screening } \\
\text { processes focussed } \\
\text { on identifying key } \\
\text { social supports for } \\
\text { client. } \\
\text { Screening } \\
\text { processes for carer } \\
\text { stress }\end{array}$ & $\begin{array}{l}\text { Focus on social } \\
\text { capacity building } \\
\text { including building } \\
\text { social networks and } \\
\text { peer supports + } \\
\text { access to } \\
\text { psychological support } \\
\text { for client and carers. }\end{array}$ \\
\hline $\begin{array}{l}\text { Acceptance / } \\
\text { Expectation }\end{array}$ & $\begin{array}{l}\text { Realistic } \\
\text { expectations of } \\
\text { therapy and } \\
\text { functional ability } \\
\text { goal }\end{array}$ & $\begin{array}{l}\text { Unrealistic } \\
\text { expectations of their } \\
\text { recovery and high } \\
\text { expectations }\end{array}$ & $\begin{array}{l}\text { Initial considerations } \\
\text { given to client's self- } \\
\text { efficacy and } \\
\text { personality factors } \\
\text { that may impact on } \\
\text { therapy participation } \\
\text { and outcomes. } \\
\text { Exploration of } \\
\text { current levels of } \\
\text { client's knowledge } \\
\text { of stroke and } \\
\text { expectation of } \\
\text { therapy. }\end{array}$ & $\begin{array}{l}\text { Access to } \\
\text { psychological therapy } \\
\text { to assist with self- } \\
\text { efficacy building. } \\
\text { Encouragement of } \\
\text { participation in } \\
\text { meaningful activities. } \\
\text { Education provided } \\
\text { to clients } \\
\text { continuously during } \\
\text { rehabilitation process } \\
\text { based on their } \\
\text { current level of }\end{array}$ \\
\hline
\end{tabular}

C The Internet Journal of Allied Health Sciences and Practice, 2020 


\begin{tabular}{|l|l|l|l|l|}
\hline & & & $\begin{array}{l}\text { Goals setting } \\
\text { completed with } \\
\text { client in context of } \\
\text { services delivery. }\end{array}$ & $\begin{array}{l}\text { Continual review of } \\
\text { client goals through } \\
\text { rehabilitation journey. }\end{array}$ \\
\hline $\begin{array}{l}\text { Ongoing Medical } \\
\text { Issues }\end{array}$ & $\begin{array}{l}\text { Good management } \\
\text { of other medical } \\
\text { conditions }\end{array}$ & $\begin{array}{l}\text { Ongoing medical } \\
\text { issues which } \\
\text { appeared to impact } \\
\text { on their recovery } \\
\text { and their ability to } \\
\text { engage with the } \\
\text { rehabilitation } \\
\text { program }\end{array}$ & $\begin{array}{l}\text { Identification of } \\
\text { medical co- } \\
\text { morbidities }\end{array}$ & $\begin{array}{l}\text { Advocacy role for } \\
\text { client to continue with } \\
\text { ongoing medical } \\
\text { medical } \\
\text { practitioners } \\
\text { involved with client's } \\
\text { care including GPs } \\
\text { and specialists. }\end{array}$ \\
\hline
\end{tabular}

When considering potential models of care for a community rehabilitation service, it is interesting to note that there is no consistent model recognized. ${ }^{2}$ There is, however, agreement regarding the importance of multi-disciplinary service provision and alignment with the ICF. ${ }^{20,21}$ This review suggests that community rehabilitation service models of care should be flexible to enable a true "client-centered" approach.

Flexible client focussed models of service delivery are increasingly becoming common within all areas of health care, including community-based rehabilitation services, to assist with both client outcomes and efficient service delivery.22,23 Such models of care focus on service delivery being delivered by highly skilled staff via a trans-professional approach to ensure the clients are able to receive the care and information they need when required. ${ }^{22}$ This flexible service model equips clinicians with a range of therapies and interventions to be offered for clients depending on their needs, rather than working from their professional skill base only. ${ }^{24}$ The concept of flexible service delivery was noted in this snapshot review and hypothesized to be associated with positive QoL outcomes. This suggests that client outcomes may be improved with flexible services, trans-professional staff within multi-disciplinary teams, and access to an array of treatment modalities dependent on client needs.

A client-centered approach has been long recognized within community rehabilitation models of care underpinned by the ICF. However, the emphasis has been on the impairment, activity, and participation paradigms and have been considered to be primarily clinician driven. ${ }^{25}$ More recently, there has been a shift towards the inclusion of complementary social and behavioral paradigms to focus more on client-centered practices. ${ }^{14}$ These paradigms tend to focus on assisting the client to develop problem-solving approaches within the current environmental, social, and psychological context. ${ }^{26}$ The importance of a holistic client focus has also been highlighted in this snapshot review with the social environment, personal factors, and comorbidity issues impacting QoL outcomes rather than solely the client's overall functional ability.

The importance of social relationships within the stroke survivor's rehabilitation journey and its impact on overall QoL is well recognized and therefore not surprising that it was suggested to be a potential influence on QoL in this snapshot review. ${ }^{27}$ Stroke survivors with excellent or good social support are more likely to demonstrate participation, which has been correlated with improved QoL..27,28 Mayo et al (2014) suggest that social capacity building is crucial within the rehabilitation process, in that participation requires a foundation of social support combined with treatment plans and positive client motivation. ${ }^{27}$ This suggests that rehabilitation models of care should carefully assess a client's current social situation and offer assistance to building and maintaining this network as required. This assessment can be complex especially with functional changes impacting family members, interpersonal relationships, life roles, communication, and participation in family activities. ${ }^{29}$ This finding highlights the importance of assessing the emotional state of carers of stroke survivors, including assessment of their anxiety levels. ${ }^{30}$ Several studies support treatment for caregiver strain and social relationships, including providing information, training, and community support for carers and the development of specialist stroke multidisciplinary teams in the community. ${ }^{31,32}$ 
As highlighted in this review, personality factors also need to be considered within community rehabilitation stroke service delivery, such as the stroke survivor's adjustment to their situation, personal factors, and outcome expectations. This study suggested that there were differences in the level of acceptance between stroke survivors with positive and negative QoL outcomes. The literature recognizes the importance of psychological factors on QoL with expectations and acceptance linked with self-efficacy and personality. ${ }^{6}$ Whilst personality may not be a modifiable factor, van Mierlo et al suggests levels of coping can change over time and that stroke survivors could benefit from psychological therapy interventions aimed towards strengthening self-efficacy. ${ }^{6}$ This indicates that community rehabilitation services should also include adjustment counselling skills and involvement in valued activities to assist with strengthening the self-efficacy of stroke survivors.

Outcome expectations may be influenced by stroke survivors' level of knowledge regarding the impact of their health condition on their recovery, which is often underestimated by health professionals. ${ }^{33}$ It is therefore important for team members to value investing time in informally assessing the client's knowledge of their condition and explore their expectations of recovery. It is thought that this may objectively clarify client expectations and provide a starting point for clinician discussions and education. ${ }^{33}$ Goal setting with stroke survivors is accepted as a usual practice point during the rehabilitation phase. However, it has specifically been found that clients whose goals are modified over time assists with the expectation of recovery and adjustment to life after stroke. ${ }^{34}$ It is therefore recommended that community rehabilitation clinicians not only set goals initially but have routine discussions with clients to adjust goals as their recovery progresses. High-level communication may also be important for clinicians needing to balance encouraging realistic expectations without diminishing client hope of recovery whilst providing evidence-based information to clients. ${ }^{35}$

This review also suggests the importance of service delivery to focus on the management of co-morbidity factors as part of routine clinical care for stroke survivors. Stroke clients have been found to have, on average, five other chronic diseases with studies suggesting that this was negatively correlated with functional outcomes and gains with rehabilitation clients. ${ }^{36}$ It is suggested that stroke care focussed on the management of clients' comorbidities may increase good outcomes on rehabilitation goals, participation, and QoL. Kubina et al suggest clinicians can carefully monitor co-morbidities and encourage clients to seek medical attention when changes are indicated, which may prevent loss of engagement in meaningful activities. ${ }^{34}$

\section{Limitations}

This review explored potential client and service factors that may contribute to QoL within the stroke community rehabilitation service context. The review is limited by the quality and validity of the client's medical records as well as the researcher's ability to extract and analyze the available data. Due to the exploratory nature of the study size, no causal relationships can be drawn.

\section{Future Research}

As this was a preliminary investigation, further research is recommended to explore the causal relationships more robustly between client and service factors and QoL in the community rehabilitation context. Each of the themes identified in this study could be explored in greater depth by including additional service assessment data (e.g. Carer Strain index results to explore the role of family relationships in rehabilitation) and including consumer interviews to further understand the influences on QoL in post stroke rehabilitation.

\section{Conclusion}

The results of this review indicated numerous factors that may contribute to QoL following stroke. As a result, service delivery within a community rehabilitation context needs to be flexible and client-centered. Services also need to consider comorbid health conditions, social, and community factors that contribute to a stroke survivor's QoL. A seamless transition for acute, subacute, or outpatient department services appears to be a key contributor to QoL.

\section{References}

1. National Stroke Foundation. Clinical Guidelines for Stroke Management. 2017. Available from: https://informme.org.au/en/Guidelines/Clinical-Guidelines-for-Stroke-Management-2017

2. Kendall $\mathrm{E}$, Muenchberger $\mathrm{H}$, Catalano $\mathrm{T}$. The move towards community-based rehabilitation in industrialised countries: Are we equipped for the challenge? Disabil Rehabil. 2009;31(26):2164-2173. [PMID:19903126] 
3. World Health Organisation. International Classification of Functioning, Disability and Health. 2001. Geneva: World Health Organisation.

4. Mayo N, Wood-Dauphinee S, Cote R, Durcan L, Carlton J. Activity Participation, and Quality of Life 6 Months Post Stroke. Arch Phys Med Rehabil. 2002 Aug;83(8):1035-1042. [PMID:12161823]

5. Moeller D, Carpenter $C$. Factors affecting quality of life for people who have experienced stroke Int $J$ Ther Rehabil. 2013;20(4) 207-216.

6. van Mierlo M., Schroder C, van Heugten C., Post M, de Kort P, Visser-Meil, M. The influence of psychological factors on health-related quality of life after stroke: a systematic review. Int J Stroke. 2014;Apr;9(3):341-348.

[PMID:24148550]

7. Ostir G, Smith P, Smith D, Beres I, Ottenbacher K. The influence of perceived pain on satisfaction with community participation after hospital discharge. Arch Phys Med Rehabil. 2005 Nov;86 (11):2095-2100. [PMID:16271554]

8. Kwok T, Lo R, Wong E, Wait-Kwong T, Mok V, Kai-Sing W. Quality of life of stroke survivors: a 1-year follow-up study. Arch Phys Med Rehabil. 2006;87(9):1177-1182.[PMID:16935051]

9. Tariah H, Hersch G, Ostwald S. Factors Associated with Quality of Life: Perspectives of Stroke Survivors. Phys Occup Ther Geriatr. 2006;25(2):33-50.

10. Lynch E, Butt Z, Heinemann A, Victorson D, Nowinski CJ, Perez L, Cella D. A qualitative study of quality of life after stroke: The importance of social relationships. J Rehabil Med. 2008 Jul;40(7):518-23. [PMID:18758667]

11. Hildebrand M. Effectiveness of Interventions for Adults With Psychological or Emotional Impairment After Stroke:

An Evidence-Based Review. Am J Occup Ther. 2015 Jan-Feb;69(1):1-9. [PMID:25553744]

12. Egan M, Davis C, Dubouloz C, Kessler D, Kubina L. Participation and Well-Being Poststroke: Evidence of Reciprocal Effects. Arch Phys Med Rehabil. 2014 Feb;95(2):262-8. [PMID:24001446]

13. Sehatzadeh, S. Effect of increased intensity of physiotherapy on patient outcomes after stroke: An evidence-based analysis. Ont Health Technol Assess Ser. 2015 Mar 1;15(6):1-42. eCollection 2015. [PMID:26356355]

14. Currin M, Patterson S, McGhee H, Kuipers P. Embedding Socio-Behavioral Frameworks in Community

Rehabilitation: Evaluation of a Service Change Program. Phys Occup Ther Geriatr. 2016;34(2-3)141-154.

15. The WHOWOQL Group. Development of the World Health Organization WHOQOL-BREF quality of life assessment. Psychol Med. 1998 May;28(3):551-8. [PMID:9626712]

16. Sarkar S, Seshadri D. Conducting Record Review Studies in Clinical Practice. J Clin Diagn Res. 2014 Sep; 8(9):JG01-JG04. [PMID: 25386466]

17. Pope C, Ziebland S, Mays N. Analysing qualitative data. In: Pope C, Mays N eds. Qualitative Research in Health Care. 2006 Blackwell Publishing Asia Pty Ltd, Melbourne: 63-101

18. Hughes A, Woodward A, Fritz M, Reeves M. Improving stroke transitions: Development and implementation of a social work case management intervention. Soc Work Health Care. 2018 Feb;57(2):95-108. [PMID:29125408] 19. Gustafsson L, Hodsoon T, Fleming J, Hoyle M. The impact of STRENGTH on the expected and actual transition to home experience. Disabil Rehabil. 2014;36(26):2244-51. [PMID:24670192]

20. Enderby P, Wade D. Community rehabilitation in the United Kingdom Clin Rehabil. 2001 Dec;15(6):577-81. [PMID:11777087]

21. Meyer T, Gutenbrunner C, Bickenbach J, Cieza A, Melvin J, Stucki G. Towards a Conceptual Description of

Rehabilitation as a Health Strategy. J Rehabil Med. 2011 Sept;43:765-769. [PMID:21826389]

22. Smith R, Duffy J. Developing a competent and flexible workforce using the Calderdale Framework. Int $J$ Ther

Rehabil 2010;17 (5):254-62.

23. Patterson S, Comas T, Pitt E, Currin M. Streamlining clinical practice in an Australian community rehabilitation service using The Calderdale Framework. Int J Ther Rehabil 2015;22(9):434-441.

24. Nancarrow S. Six principles to enhance health workforce flexibility. Hum Resour Health. 2015 Apr 7;13:9.

[PMID:26264184]

25. Graven C, Brock K, Hill K, Ames D, Cotton S, Joubert L. From rehabilitation to recovery: protocol for a randomised controlled trial evaluating a goal-based intervention to reduce depression and facilitate participation post-stroke. BMC Neurol. 2011 Jun;18;11:73. [PMID:21682910]

26. Nieuwenhuijsen E, Zemper E, Miner K, Epstein, M. Health behavior change models and theories: contributions to rehabilitation. Disabil Rehabil. 2006 Mar 15;28(5):245-56. [PMID:16492619]

27. Mayo N, Bronstein D, Scott S, Finch L, Miller S. Necessary and Sufficient causes of participation post-stroke: practical and philosophical perspectives. Qual Life Res. 2014 Feb;23(1):39-47. [PMID:23754685]

28. Kwok T, Pan J, Lo R, Song X. The influence of participation of health related quality of life in stroke patients.

Disabil Rehabil. 2011;33(21-22):1990-6. [PMID:21955053]

(๑) The Internet Journal of Allied Health Sciences and Practice, 2020 
29. Green T, King K. (2011) Relationships between biophysical and psychological outcomes following minor stroke. Can J Neurosci Nurs. 2011;33(2):15-23. [PMID:21977768]

30. Greenwood N, Mackenzie A. An exploratory study of anxiety in carers of stroke survivors. J Clin Nurs. 2010 Jul;19(13-14):2032-8. [PMID:20920029]

31. Aguirrezabel A, Duarte E, Rueda N, Cervantes C, Marco E, Escalada F. Effects of information and training provision in satisfaction of patients and carers in stroke rehabilitation. NeuroRehabilitation. 2013;33(4):639-47. [PMID:24018368]

32. Lincoln N, Walker M, Dixon A, Knights P. Evaluation of a multiprofessional community stroke team: A randomized control trial. Clin Rehabil. 2004 Feb;18(1):40-7. [PMID:14763718]

33. McPhail S, Haines T. Patients undergoing subacute rehabilitation have accurate expectations of their healthrelated quality of life at discharge. Health Qual Life Outcomes. 2012 Aug 17;10:94. [PMID:22901009]

34. Kubina L, Dubouloz C, Davis C, Kessler D, Egan M. The process of re-engagement in personally valued activities during the two years following stroke. Disabil Rehabil. 2013 Feb;35(3):236-4. [PMID:22691088]

35. Wiles R, Ashburn A, Payne S, Murphy C. Patients' expectations of recovery following stroke: a qualitative study. Disabil Rehabil. 2002 Nov 10;24(16):841-50. [PMID:12450460]

36. Nelson M, Kelloway L, Dawson D, McClure A, McKellar K, Menon A. at al. Stroke rehabilitation and patients with multi-morbidity: a scoping review protocol. J Comorb. 2015;5: 1-10. [PMID: 29090155]

(C) The Internet Journal of Allied Health Sciences and Practice, 2020 